\title{
Cosmopolitanism Orientation and Fashion Consciousness of Educated Young Consumers of Fashion Related Products in Sri Lanka
}

\author{
P. G. S. A. Jayarathne \\ University of Sri Jayewardenepura, Sri Lanka \\ B. N. F. Warnakularsooriya \\ University of Sri Jayewardenepura, Sri Lanka
}

\begin{abstract}
Cosmopolitanism has become an integral part of social systems. Fashion consciousness is also a central aspect of the self of the fashion consumer. Thus, cosmopolitanism orientation may be one of the main determinants of fashion consciousness in the world at large regardless the geographical proximity. Most of the studies centred on cosmopolitanism, fashion consciousness, and fashion related products are based upon developed countries reflecting the seldom of developing country-based research. Addressing such gaps in the literature this scrutiny firstly aims to assess the degree of cosmopolitanism orientation in Sri Lankan young consumers, secondly to examine whether or not cosmopolitism orientation varies across the different ethnic groups, and thirdly to examine whether cosmopolitanism orientation discriminates the high from moderate, and moderate from low degree of fashion consciousness of Sri Lankan young educated consumers by performing Multiple Discriminant Analysis. A survey was carried out taking university students as the proxy for Sri Lankan younger generation. 663 usable questionnaires were used for the analysis. The result uncovers that Sri Lankan educated young consumers possess moderate degree of
\end{abstract}

Corresponding Author:

P.G.S.A. Jayarathne is a Senior Lecturer at the Department of Marketing Management, University of Sri Jayewardenepura, Nugegoda, Sri Lanka. E-mail: amilaj@sjp.ac.lk 
cosmopolitanism orientation and that Sinhalese are more open to Western Values than Tamil and Muslim Community. The results of Multiple Discriminant Analysis divulge that cosmopolitanism orientation discriminates the high from moderate, and moderate from low degree of fashion consciousness though the discriminating power is weak. Finally the paper makes important implications and suggestions for practitioners as well as for academics in the field of fashion and fashion related products.

\section{Keywords}

Cosmopolitanism Orientation, Fashion Consciousness, Fashion Products

\section{Introduction}

Cosmopolitanism has been considered an integral part of social systems. In expressing the self-identity and in shaping the life-style a community centred in one culture is highly influenced by the other cultures in the world as a result of rapid globalization. Global economic growth has inevitably brought about increased wealth accumulation and consumption of foreign material goods, especially Western products (Alden, Steenkamp \& Batra, 2006). This in turn has led to a rise in cosmopolitanism, characterised by consumer openness to foreign products, and admiration of and desire to own products associated with a Western lifestyle (Alden et al., 2006; Cleveland \& Loroche, 2007; Cleveland, Erdogan, Arikan \& Poyraz, 2011).

Cosmopolitanism, which refers to adopting cultures, values, and lifestyle from other countries without abandoning one's own cultural values, posits combines global and local values. Many researchers have identified fashion and fashion products specially clothing, accessories and footwear as a product category closely associated with self-identity and lifestyle(Alden et al., 2006; Cleveland et al., 2007).Fashion and clothing preference displays a person's self-concept, or how an individual would like to be(Cleveland et al., 2011). Thus, clothing fashions and various aspects of consumer's self are highly related and an increasing amount of research has been expended on the aspects of self of fashion consumers.

Clothing fashions and aspects of consumer's self are highly related and an increasing amount of research has been expended on aspects of self of fashion consumers. Fashion consciousness, which refers as a person's 
degree of involvement with the styles or fashion, is also a central aspect of the self of the fashion consumer. Fashion consciousness has been subject to a considerable degree of investigation, and is a central aspect of the self of the fashion related products' consumers. However, most of the studies (e.g. Rathnayaka, 2011) related to fashion consciousness have been conducted in the developed countries, and comparatively very limited attention has been paid on fashion consciousness of consumers in developing countries. An increasing amount of evidence suggests that the attitudes, beliefs and perceptions of fashion consumers in developed countries are different in a significant manner from those in developing countries. For instance, compared to consumers in developed countries, consumers in developing countries tend to have more favourable attitudes toward products from developed countries than domestic products (LaTour \& Henthorne, 1990, Dickson, Lennon, Montalto, Shenn \& Zhang, 2004). Accordingly, fashion consciousness of consumers in developing countries needs to be assessed as it has not been adequately researched.

Clothing and fashions were one of the main aspects through which influence of Western occurred in many developing countries including Sri Lanka. Sri Lankan young consumers are exposed to many trends in the fashion is considered to be one of the main aspects where Sri Lankan consumers increasingly adopt Western styles. It is well accepted that fashion consumers in Sri Lanka, especially youngsters, are tempted to merely adopt Western clothing styles with less understanding of the functions of various fashions such as freedom, uniqueness, and other characteristics of modernity. Being a country with a unique and strong culture grounded mainly on cultural bases, Sri Lanka has its own beliefs, norms and attitudes which might shape consumers' behaviour. Therefore, fashion consumers should have a mental conflict between two choices, adopt Western fashions or obey the rules of their own culture (Rathnayaka, 2011). Further, education level matters a lot either to accept or to reject cultural attributes from others' culture and consequently their consumption behaviour, (Kotler\& Keller, 2009). Thus, it is important and need to study the behaviour of young educated generation in Sri Lanka.

Cosmopolitan orientation may highly be associated with the fashion consciousness in the world at large regardless the geographical proximity. 
Most of the studies centred on cosmopolitanism and fashion consciousness in fashion related products have been carried out in developed countries reflecting the dearth of developing country based research, specially based on Sri Lanka (Dickson et al., 2004). It reflects that it is yet questionable on the level of cosmopolitism orientation, whether or not cosmopolitism orientation varies across the different ethnic groups, and whether or not such orientation discriminates the degree of fashion consciousness of the educated youngsters in Sri Lanka.

Addressing such gaps in the literature this scrutiny first aims to assess the degree of cosmopolitan orientation in educated young consumers in Sri Lanka, and secondly to examine whether or not cosmopolitism orientation varies across the different ethnic groups, and thirdly to examine whether the cosmopolitan orientation discriminates the high from moderate, and moderate from low degree of fashion consciousness of the young consumers in the fashion related products in Sri Lanka.

The paper is structured as follows. Firstly it discussed the key literature around the Fashion Consciousness and Cosmopolitism. Then the methodological aspects of the study are discussed. Thirdly, the validation of measurement properties and analysis are presented. In the fourth section the findings are discussed linking with the literature. Finally, the paper makes the concluding remarks and suggests direction for future studies.

\section{Literature Review}

\section{Cosmopolitism Orientation (CO)}

Rapid globalization and interaction with people from other countries has brought about changes in the values and lifestyles of consumers; thus openness to other cultures and concern for global and social media has become an integral part of social systems. Cosmopolitanism refers to adopting cultures, values, and lifestyle from other countries without abandoning one's own cultural values. Thus, cosmopolitanism embedded with global and local values (Yoon, Cannon \& Yaprak, 1996). Global cosmopolitans are individuals who imbibe global values and believe that global values are superior to their own local cultural values. Local cosmopolitans place importance on local culture while appreciating other cultures. 
Some studies on culture reveal that globalization has brought significant changes in consumers' lifestyles. For instance, Jin and Kang (2011) disclose that Chinese consumers were influenced by western values and had moved away from a collectivist orientation. Further, the study of Demangeot and Sankaran (2012) shows that consumption pattern of Indians living in US is different from that of Indians living in India. Cleveland et al. (2011) disclosed that demographic variables including ethnic groups had a significant impact on cosmopolitanism. Further, such study discloses the important of ethnic groups for cosmopolitism than other demographic variables such as age, gender, income level.

Despite the rapid exposure to the globalization, consumers in a country like Sri Lanka which had been colonized by Dutch, Portugal and Britain as well as highly influenced by the Indian and other Asian cultures. Further, people especially youngsters in Sri Lanka are more exposed to the global values/fashions through increased use of internet and social media. However, it is yet questionable owing to these influencers whether or not Sri Lankan youngsters possess cosmopolitism orientation. Further, according to the Kotler and Keller (2009) education level matter for cultural adoption, as well as strongly influence the decision making pattern of the people. However, in Sri Lankan context it is not yet addressed in the literature how young educated generation reacting to western culture; which reflects the cosmopolitanism orientation. Therefore, Sri Lanka as a multi-ethnic country, it is doubtful on the nature of cosmopolitism orientation of different ethnic groups.

Addressing this gap in the literature, current scrutiny expects firstly to assess the degree of cosmopolitism orientation, secondly to examine whether or not cosmopolitism orientation varies across the different ethnic groups of the educated young consumers of fashion related products and finally to discriminate.

\section{Fashion Consciousness (FC)}

Owing to the dynamic nature of the fashion market, an individual must frequently re-evaluate himself and the meanings attached to the styles that he has adopted to remain current (e.g. Miller, Cowan \& Hetherington,1993). 
Thus, fashion consciousness, is also a central aspect of the self of the fashion consumer.

Although fashion consciousness as a concept has started discussing in 1980s along with Self-Consciousness Theory, Gould and Stern (1989) strengthen it stressing the importance of gender. Nam, Hamlin, Gam, Kang, Kim, Kumphai, Starr\& Richards (2006) explain fashion consciousness as ' a person's degree of involvement with the styles or fashion of clothing'. An individual does not have to be either a fashion opinion leader or a fashion innovator to be considered fashion conscious. "Rather, fashion consciousness relates to a person's interest in clothing and fashion and his appearance" (Summers, 1970; Jonathan \&Mills, 1982).

Since materialism has been argued to be a key influencer in constructing a sense of self-identity, it is unsurprising that many studies have shown gender to be an important variable in fashion clothing consumption. The study of Gould and Stern (1989) shows that females are more fashion consciousness than males; also those who are higher in gender consciousness are more fashion consciousness; those who are publicly selfconscious are more fashion consciousness. A study of fashion consciousness in Eastern European markets highlighted that young male respondents were more fashion-conscious than their female counterparts (Manrai, Lascu, Manrai \& Babb, 2001). According to Bakewell, Mitchell \& Rothwell (2006) marketers are increasingly recognizing that it is 'outmoded' to consider men as 'producers' and women as 'consumers'. However, many authors suggest that "although appearance consciousness has a greater influence on women, the society re-defines what it means to be a 'man'. Therefore, the notion of fashion-less male is outmoded"' (Patterson \& Elliot, 2002).

\section{Cosmopolitism Orientation and Fashion Consciousness}

Scholars have paid the attention on exploring the association and/or influence of cosmopolitism orientation and/on fashion consciousness. Cosmopolitism brings cultural and social influence to the people's lifestyle and identity. Lifestyle and identity has a close affiliation with the fashion consciousness. Such argument has been supported by the below discussed literature. 
Featherstone (1995) shows how men have altered their cultural norms and whereby how they are encouraged to see their social value as being determined by what they look like. This shift has been recognized an inevitable development of the post-modern economy. Following such argument Bakewell et al. (2006) note how post-modernism, increasing peer group socialization, taking sportsmen as models, liberation in Gay relationship, and multiculturalism influence the self and appearance consciousness of the male generation in UK.

Greco and Paksoy (1989) noted that fashion-conscious shoppers rely more on mass media information sources than non-fashion-conscious customers. Walsh, Mitchell and Thuran (2001) highlighted that fashion consciousness among German consumers was due to the desire for up-todate styles, frequent changes in wardrobe and pleasurable shopping experiences.

Cosmopolitism orientation has implications in consumption patterns of customers including brand selection. For instance, Cannon and Yaprak, (2002); Riefler and Diamantopoulos (2009) disclose that cosmopolitan consumers as open-minded world citizens, whose consumption orientation transcends any particular cultural setting. The studies of Riefler, Diamantopoulos and Siguaw (2012); Skrbis, Kendalland Woodward (2004) found out that cosmopolitan consumers' desire to experience culturally diverse products arises from their open-mindedness to cultural differences. This desire also enhances attitudes towards global advertising (Zhou \& Belk, 2004). An open mindset implies a propensity to accept new ideas, which can mitigate potential fallout from negative perceptions of foreign advertisements (Kwak et al., 2006). Lee and Mazodier (2015) found out that cosmopolitism has implications on brand but not on brand trust.

Fashion products, viz, clothing, accessories, and foot wear are known as the product categories which have close association with self-identify and lifestyle. The study of Khare, Mishra, Parveen and Srivastava (2011) shows that global value and culture influence consumers' involvement with and choice of fashion clothing. Khare (2014) discusses cosmopolitanism as an antecedent to fashion clothing involvement. Worth noting is that most of the studies centred on cosmopolitanism and fashion related products are based 
upon developed countries reflecting the seldom of developing country based research. In addition, existing studies in this context have mostly concerned on clothing products only, have not taken the complete fashion product category - clothing, accessories, and footwear - on board.

Even though the above discussion of literature reflects that cosmopolitism orientation may discriminate the Fashion consciousness it has not been comprehensively investigated with empirical evidence. Thus, addressing such need in the literature current study sets the third objective to examine whether or not cosmopolitism orientation discriminate the fashion consciousness of young educated consumers of fashion related products in Sri Lanka. Supporting the above review of the literature following hypotheses is derived.

H1: The degree of cosmopolitism orientation of young educated consumers in Sri Lanka is at a high level

$\mathrm{H} 2$ : The degree of cosmopolitism orientation of young educated consumers in Sri Lanka significantly varies across the ethnic groups in Sri Lanka.

H3: The degree of cosmopolitism orientation of young educated consumers in Sri Lanka discriminate the high from moderate, and moderate from low degree of their fashion consciousness.

\section{Methodology}

This is an explanatory study which is aiming at assessing the degree of cosmopolitism orientation, examining whether such orientation varies among the ethnic groups, and testing whether or not cosmopolitism orientation discriminates the high from moderate, and moderate from low degree of fashion consciousness. Population of the study is educated young consumers of fashion related products (clothing, accessories, and footwear) in Sri Lanka. It was assumed that the representation of young educated consumers is in the state universities in Sri Lanka. University undergraduate and postgraduate students were considered as the proxies of the study. A sample of 750 undergraduate and postgraduate students from selected five main state universities - University of Sri Jayewardenepura, University of Colombo, University of Moratuwa, University of Kelaniya and University of Peradeniya-was drawn. It reflects that the sample of the study is selected according to the judgmental sampling techniques. A selfadministrated questionnaire was used in the survey as the data collection 
instrument. The survey was carried out in June, 2015 and 663 filled questionnaires were used for the analysis. The questionnaire was divided into three sections. The first section of the questionnaire dealt with the cosmopolitism orientation of the consumers and the second section was focused on the fashion consciousness of the consumers, the third section was on general demographic information. The questionnaire was first prepared in English and was then translated into Sinhala, and again into the English by an independent person to ensure the accuracy of translation.

Measurement scales developed on a priori basis have been used in the study. Cosmopolitan scale was adapted from acculturation scale developed by Cleveland and Loroche (2007). Even though it contains several subdimensions, only cosmopolitan sub-dimension comprising of eleven items was adopted. The scale used by Bakewell and Rothwell (2006) was extracted to measure fashion consciousness. Such scale was initially used by Gould and Stern (1989). In total, 29 fashion consciousness indicators were employed in the adopted questionnaire. Even though the original scale included questions on fashionable underwear, they were excluded from the current scale since Sri Lankan consumers pay less attention to fashionable under garments. Styles in under garments are still not popular in Sri Lanka and people hesitate to express their views regarding undergarments openly; particularly, by the female consumers. Five-point Likert scale was used for both scales ranging from strongly disagree (1), neutral (3) to strongly agree (5). All the ratings given by the respondents to the degree of fashion consciousness were summated to take the mean values of the construct and the mean values were grouped into three categories, low, medium, and high using the decision criteria given in Table 1. These groups were used for performing Discriminant Analysis.

Table 1: Decision criteria - Degree of Fashion Consciousness (FC)

\begin{tabular}{|l|l|}
\hline Mean Values & Decision \\
\hline $1.00-2.49$ & Low degree of Fashion Consciousness \\
\hline $2.5-3.49$ & Medium degree of Fashion Consciousness \\
\hline $3.5-5.00$ & High degree of Fashion Consciousness \\
\hline
\end{tabular}




\section{Analysis and Results}

\section{Validation of the Measurement Properties}

Major psychometric properties of the measurement scales of cosmopolitism and fashion consciousness constructs were established through validity (content and construct) and reliability.

Content validity ensures that the measure includes an adequate and representative set of items that taps the domain of the concept (Malhothra 2005; Sekaran, 2004). The scales developed by Cleveland and Loroche (2007) and Bakewellet al. (2006) were extracted for this study to ensure the content validity. Construct validity evaluates how well scale of a construct actually measures that construct (Peter, 1981). According to Peter (1981) this includes the measures of unidimensionality, reliability, convergent validity and discriminant validity.

Unidimensionality, the items of the scale estimate one factor (Dunn, Wellman \& Bevan, 1994), was established by performing Confirmatory Factor Analysis (CFA) provided by AMOS 16 version statistical package. The CFA which describes how well the observed indicators serve as a measurement instrument for the latent variables, provides a more rigorous test of unidimensionality (Garver \& Mentzer 1999).To ensure that each construct is measured by multiple indicators and each of the indicators measures only a single construct, both cosmopolitism and fashion consciousness scales were examined for unidimensionality. Even though the scale by Cleveland and Loroche (2007) used for measuring the cosmopolitism had only sets of indicators, in the Sri Lankan context two factors/dimensions were derived namely, cosmopolitism for lifestyle and cosmopolitism for consumption. The overall measurement model fit is assessed with Goodness of Fit Indices (GOF).GOF values for both cosmopolitism and fashion consciousness are summarized in Table 2. 
Table 2:Goodness of Fit Indices (GOF) for Cosmopolitism (COS) and Fashion Consciousness (FC)

\begin{tabular}{|c|c|c|c|}
\hline Fit Indices & COS & Fashion Consciousness & Acceptable Limit \\
\hline CMIN/DF & 2.178 & 1.876 & Ratio of 3 to 1 \\
\hline GFI & 0.954 & 0.966 & 0.90 or greater \\
\hline AGFI & 0.918 & 0.907 & 0.90 or greater \\
\hline CFI & 0.965 & 0.912 & 0.90 or greater \\
\hline NNFI/TLI & 0.907 & 0.923 & 0.90 or greater \\
\hline RMSEA & 0.042 & 0.048 & 0.05 or less \\
\hline
\end{tabular}

The results in Table 2 indicate that, all the model fit indices are within acceptable limit ensuring the satisfactory overall fit of cosmopolitism orientation and fashion consciousness measurement scales.

For cosmopolitism orientation and fashion consciousness measurement scales, diagnosis indicators for evaluating components of measurement scale such as standardized residuals and modification indices, and the direction, magnitude, and statistical significance of the parameter estimates between indicators and latent variables were also examined, (Garver \& Mentzer, 1999). For both these scales standardized residual are below 2.58 at 0.05 alpha level and modification indices are below 7.88 (results are not shown due to space limitation). The standardized parameter estimates for the measurement scales are greater than 0.70 and exhibit the correct sign and magnitude. Critical ratios of regression weight of the items are statistically significant at 95 percent confidence level for the first and second order latent variables. Strong evidence of unidimensionality of the constructs exists when the parameter estimates are greater than 0.70 , are statistically significant, and are in the right direction (Garver \& Mentzer, 1999).

One of the aspects of the reliability is internal consistency. The internal consistency of the indicators of the first order factors of cosmopolitan orientation and indicators of fashion consciousness was assessed through by calculating Cronbach's alpha value, (Malhothra, 2005). The standardized Cronbach's alpha for all the dimensions exceeds threshold value 0.7 ensuring the internal consistency of the scale. The results are summarized in Table 3. 
Table 3: Assessment of internal consistency

\begin{tabular}{|l|c|}
\hline Latent Variable & Cronbach's Alpha Value \\
\hline COS for Lifestyle & 0.848 \\
\hline COS for Consumption & 0.768 \\
\hline Fashion Consciousness & 0.837 \\
\hline
\end{tabular}

Convergent validity refers to the extent to which the latent variable correlates to items designed to measure the same latent variable (Garver \& Mentzer, 1999). It is assessed through Composite Reliability (CR) and Average Variance Extracted (AVE). The respective values and the acceptable levels are given in Table 4.

Table 4: Assessment of convergent validity

\begin{tabular}{|l|c|c|}
\hline & $\begin{array}{c}\text { Composite } \\
\text { Reliability }\end{array}$ & $\begin{array}{c}\text { Average Variance } \\
\text { Extracted }\end{array}$ \\
\hline Cosmopolitism for the lifestyle & 0.835 & 0.627 \\
\hline Cosmopolitism for the consumption & 0.795 & 0.576 \\
\hline Fashion consciousness & 0.775 & 0.521 \\
\hline
\end{tabular}

Discriminant validity refers to the extent to which the items are indeed novel and not simply a reflection of some other variable (Garver \& Mentzer, 1999). Discriminant validity was established by comparing the squared paired correlation values between all possible pairs of constructs with AVE of respective dimensions, and verifying that they were lower than the respective AVE values. The results are given in Table 5.

Table 5: Assessment of discriminant validity

\begin{tabular}{|l|c|c|c|}
\hline & $\begin{array}{c}\text { COS for } \\
\text { Lifestyle }\end{array}$ & $\begin{array}{c}\text { COS for } \\
\text { Consumption }\end{array}$ & $\begin{array}{c}\text { Fashion } \\
\text { Consciousness }\end{array}$ \\
\hline COS for Lifestyle & $\mathbf{0 . 6 2 7}$ & & \\
\hline COS for Consumption & 0.360 & $\mathbf{0 . 5 7 6}$ & \\
\hline Fashion Consciousness & 0.179 & 0.206 & $\mathbf{0 . 5 2 1}$ \\
\hline
\end{tabular}

Note: Bold figures are AVE values and in italics are the squared paired correlation values. 


\section{Degree of Cosmopolitism Orientation of Young Educated Consumer of Fashion Products in Sri Lanka}

The first objective and hypotheses of the study are related to the degree of cosmopolitan orientation. Table 6.1 reports the mean value of the responses given for the cosmopolitan orientation. The mean value (2.885) of the cosmopolitan lies on the moderate level as the mean value is calculated by taking the average of the summation of all responses given to the five point Likert scale where midpoint is moderate. However, to examine whether the statistical significant difference exists between the observed mean value (2.885) and assumed mean value of the lower boundary (2.5) and upper boundary (3.5) of the moderate level one sample t-test was performed.

Table 6.1: Mean and Standard Deviation (SD) values of COS

\begin{tabular}{|c|c|c|c|c|}
\hline & $\mathbf{N}$ & Mean & SD & Std. Error Mean \\
\hline $\operatorname{COS}$ & 663 & 2.885 & .62029 & .05065 \\
\hline
\end{tabular}

The results of the $t$ test are given in Table 6.2. As per Table 6.2, it is evident that the statistically significant difference exists between observed mean value (2.885) and the assumed means (2.5, and 3.5) at $\alpha=0.00$.

Table 6.2: One-Sample test results for COS

\begin{tabular}{|l|c|c|c|}
\hline Assume Mean & $\mathbf{t}$ & Df & Sig. (2-tailed) \\
\hline COS at TV $=2.5$ & 7.602 & 662 & .000 \\
\hline COS at TV $=3.5$ & -18.333 & 662 & .000 \\
\hline
\end{tabular}

Note: $\operatorname{COS}=$ Cosmopolitism, TV $=$ test value

Therefore, it reflects that the degree of cosmopolitism orientation of the young educated consumers of fashion items in Sri Lanka is at a moderate level, while rejecting the null hypothesis $(\mathrm{H} 1)$.

\section{Cosmopolitism Orientation in Different Ethnic Groups}

The second objective is to examine whether the degree of cosmopolitism orientation of educated young consumers significantly varies among the ethnic groups and the second hypothesis is related to the objective. 
Table 7: Descriptive statistics of COS in different ethnic groups

\begin{tabular}{|c|c|c|c|c|}
\hline \multirow{2}{*}{ COS SIN } & $\mathbf{N}$ & Mean & Std. Deviation & Std. Error \\
\cline { 2 - 5 } & 362 & 2.9444 & .73064 & .08611 \\
\hline TM & 138 & 2.8125 & .62222 & .11759 \\
\hline MU & 118 & 2.5431 & .65147 & .12098 \\
\hline OTHER & 45 & 2.3810 & .80086 & .17476 \\
\hline Total & 663 & 2.7633 & .73262 & .05982 \\
\hline
\end{tabular}

Note: SIN = Sinhala; TM= Tamil; MU= Muslim

The mean values of the degree of $\mathrm{CO}$ of young educated consumers of fashion items (Table 7) are slightly different among the ethnic groups. To test whether these differences are statistically significant, one way ANOVA test was performed.

Table 8 : ANOVA results for $\mathrm{COS}$ in different ethnic groups

\begin{tabular}{|c|l|c|c|c|c|c|}
\hline & & $\begin{array}{c}\text { Sum of } \\
\text { Squares }\end{array}$ & Df & $\begin{array}{c}\text { Mean } \\
\text { Square }\end{array}$ & F & Sig. \\
\hline \multirow{2}{*}{ COS } & $\begin{array}{l}\text { Between } \\
\text { Groups }\end{array}$ & 6.906 & 3 & 2.302 & 4.600 & .004 \\
\cline { 2 - 7 } & $\begin{array}{l}\text { Within } \\
\text { Groups }\end{array}$ & 73.067 & 659 & .500 & & \\
\cline { 2 - 7 } & Total & 79.973 & 662 & & & \\
\hline
\end{tabular}

As per the results of the test (Table 8), the degree of cosmopolitism orientation of young educated consumers of fashion items significantly varies among the ethnic groups: Sinhala (SIN), Tamil (TM), Muslim (MU) and other (eg. Burger, Male). Among these ethnic groups Sinhala community records relatively a higher degree of cosmopolitism orientation and it is significantly different from that of other ethnic groups.

\section{Cosmopolitism Orientation and Fashion Consciousness}

The third objective of this paper is to investigate whether or not cosmopolitism orientation discriminates the high from moderate, and moderate from low degree of fashion consciousness; and third hypothesis is related this objective. The degree of fashion consciousness was grouped as 
High, Medium, and Low according to the criteria given in Table 1. Respective mean values of the $\mathrm{CO}$ of each group are given in Table 9. As shown in Table 9 mean values of $\mathrm{CO}$ among the three fashion consciousnessgroups are descriptively different.

Table 9: Mean of classified by categories

\begin{tabular}{|l|c|c|}
\hline & Mean & Std. Deviation \\
\hline Low Fashion Conscious & 2.675 & 0.378 \\
\hline Moderately Fashion Conscious & 2.738 & 0.583 \\
\hline Highly Fashion Conscious & 3.085 & 0.252 \\
\hline
\end{tabular}

Multiple Discriminate Analysis (MDA) was performed to test whether the groups were correctly classified in terms of the given criteria. The MDA is appropriate when the dependent variable is non-metric (categorical) and the independent variables are metric (Malhothra, 2005). To run the MDA the sample was divided into two parts: analysis sample (496 respondents) and validation sample (167 respondents). The analysis sample was used for estimation of discriminant function and the validation sample was reserved for validating the discriminant function (Malhothra, 2005). The results of MDA are given in Table 10 and 11. The results in Table 8 show the Canonical Discriminant function. According to the results, the eigenvalue associated with the first function is 0.086 , and this function accounts for 81.5 percent of the explained variance. The canonical correlation associated with this function is 0.279 . The square of this correlation indicates that 8 percent of the variance in the fashion consciousness is explained or accounted by this model. The second function has an eigenvalue of 0.020 and accounts for only 18.5 percent of the explained variance. The canonical correlation associated with this function is 0.141 . The square of canonical correlation of this function indicates that 2 percent of the variance in the fashion consciousness is explained or accounted for by this model. Because, the eigenvalue and canonical correlation are larger, the first function is likely to be superior. 
Table 10: Canonical discriminant function - Eigenvalues

\begin{tabular}{|c|c|c|c|c|}
\hline Function & Eigenvalue & $\begin{array}{c}\text { \% of } \\
\text { Variance }\end{array}$ & Cumulative \% & $\begin{array}{c}\text { Canonical } \\
\text { Correlation }\end{array}$ \\
\hline 1 & $.086^{\mathrm{a}}$ & 81.5 & 81.5 & .279 \\
\hline 2 & $.020^{\mathrm{a}}$ & 18.5 & 100.0 & .141 \\
\hline
\end{tabular}

a. First 2 canonical discriminant functions were used in the analysis.

Table 11, which reports the results that are used to determine the significance of the discriminant function, shows that the value of Wilks' Lambda is 0.914 if no function is removed. The Wilks' Lambda transforms to a chi-square of 16.226 , with 8 degrees of freedom, which is significant at 95percent confidence level. The Wilks' Lambda is near to 1 and, thus the two functions together significantly discriminate among the three groups. However, when the first function is removed, the Wilks' Lambda associated with the second function is 0.476 , which is close to 0 , but is not even significant at the 95percent confidence level. Therefore, the second function does not contribute significantly to group differences.

Table 11: Canonical discriminant function - Wilks' Lambda

\begin{tabular}{|c|c|c|c|c|}
\hline Test of Function(s) & Wilks' Lambda & Chi-square & df & Sig. \\
\hline 1 through 2 & .914 & 16.226 & 8 & .042 \\
\hline 2 & .476 & 3.216 & 3 & .361 \\
\hline
\end{tabular}

Some idea about the relative importance of predictors in discriminating the degree of $\mathrm{CO}$ can be obtained by examining the absolute magnitude of the standardized discriminant function coefficients and the structure correlations (Malhothra, 2005). Generally, predictors with relatively large coefficients contribute more to the discriminating power of the function, as compared with predictors with smaller coefficients and are, therefore, more important (Malhothra, 2005).

Table 12: Standardized canonical discriminant function and structure matrix

\begin{tabular}{|l|c|c|c|c|}
\hline \multirow{2}{*}{} & \multicolumn{2}{|c|}{$\begin{array}{c}\text { Standardized Canonical Discriminant } \\
\text { Function Coefficients }\end{array}$} & \multicolumn{2}{c|}{ Structure Matrix } \\
& \multicolumn{2}{|c|}{ Function } & \multicolumn{2}{c|}{ Function } \\
\cline { 2 - 5 } & 1 & 2 & 1 & $.782 *$ \\
\hline COSLS & .854 & .270 & $.966^{*}$ & .199 \\
\hline COSCN & .923 & -.453 & & \\
\hline
\end{tabular}


An examination of the absolute magnitude of the standardized discriminant function coefficient and the structure correlation reported in the Table 12 respectively indicates that the Cosmopolitism Orientation in Life Style (COSLS) and the Cosmopolitism Orientation in Consumption (COSCN) are the most important predictors in discriminating the three groups of fashion consciousness.

In summary, it is appeared that the degree of cosmopolitism orientation discriminates the high from moderate, and moderate from low degree of fashion consciousness though its discriminating power is weak, only 8 percent of the variance of fashion consciousness is explained or accounted by the degree of cosmopolitism.

On a priori basis, researchers assumed that cosmopolitism orientation would have an association with fashion consciousness. It is supported by the empirical findings as it discloses that the degree of Cosmopolitism Orientation discriminates the high from moderate, and moderate from low degree of fashion consciousness. In turn, it provides evidence for nomological validity; because nomological validity is demonstrated when the empirical estimation shows a strong relationship between exogenous (Cosmopolitism Orientation) and endogenous (Fashion Consciousness) variables depicted in the theory.

\section{Discussion and Conclusion}

This study is aimed for three objectives; 1) to assess the degree of cosmopolitism orientation of young educated consumers of fashion related products in Sri Lanka, 2) to examine whether or not cosmopolitism of young educated consumers varies across the different ethnic groups, 3) to examine whether or not cosmopolitism orientation discriminate fashion consciousness. Objectives were empirically achieved taking 663 students in the five main state universities as proxies for the young educated fashion consumers in Sri Lanka.

The study initially assumes that Sri Lanka young educated consumers are highly cosmopolitism orientated and more willing to accept the foreign cultural attributes and foreign products. However, the empirical findings show that the degree of cosmopolitism orientation in this context is at a 
moderate level. It reflects that Sri Lankan young educated consumers are still maintaining concern on national/local culture even though they are in the process of the socio-cultural changing journey. However, it reflects that they equally rather slightly value foreign phenomena more than local phenomena. This is in line with the finding Jin and Kang (2011) study that disclose that Chinese young consumers were influenced by western values and had moved away from a collectivist orientation. As in an Asian country, Sri Lankan educated young consumers also reflect the same change.

Secondly, the study disclosed that cosmopolitism orientation of the Sri Lankan educated youngsters significantly varies across the different ethnic groups. It shows that Sinhalese are more influenced by western inputs than Tamil and Muslim community respectively. Current knowledge, in particular Cleveland et al. (2011), disclosed that demographic variables including ethnic groups had a significant impact on cosmopolitanism. It is empirically supported by the current scrutiny.

Thirdly, the study discloses that degree of fashion consciousness of the young educated fashion consumers is discriminated by the cosmopolitism orientation of them the discriminating power is weak though. It shows that fashion consciousness of the consumers depends not only upon the extent of their openness to the western values but also upon other factors which needs to explored through a future study. Bakewell et al. (2006) also noted that fashion/self-consciousness of the people is being influenced by several factors other than their flexibility to others' cultural values. Further, discriminating ability of cosmopolitism orientation for the fashion consciousness is in line with outcomes of the studies of Khare et al. (2011), Khare (2013), and Walsh et al. (2001), though none of such study specifically addressed the knowledge contributed by the current study.

It is noteworthy that the study contributes to the existing theory in several terms. Firstly, the scales used for assessing the cosmopolitanism orientation and fashion consciousness were adopted and validated in the developing country's context (i.e. Sri Lankan context). In fact, lack of developing country based research has already being noted by few authors (e.g. Khare, 2013). 
Secondly, the diversity of cosmopolitan orientation reveals among the different ethnic groups is consistent with the finding of Cleveland et al. (2011). Thirdly, this scrutiny shows that cosmopolitanism orientation positively and significantly discriminates the degree of fashion consciousness of the consumers of fashion products. It empirically supports the findings of few existing studies; for instance Khare (2013).

Some existing research (e.g. O'Connor, Friel \& Kelleher, 1997; Lertwannawit \& Mandhachitara, 2012) have implied influence of fashion consciousness on fashion clothing. Current study certainly extends them explicitly uncovering not only the fashion consciousness in fashion clothing but also its relationship with the cosmopolitism orientation of the consumers. On top of that, investigating the entire category of fashion products also adds value to the knowledge as most of the literature has taken only clothing products on board.

The findings not only contribute to the knowledge in the relevant fields, but also provide empirical evidence to some previous works in the literature. Findings provide valuable insights for marketers, managers and for companies at large to successfully design and maintain their competitive strategies in the fashion product category in Sri Lanka. Specially for retailers in the fashion category targeting Sri Lankan youngsters in selecting their styles, in deciding the varieties of the product ranges, frequency in changing designing, and in launching promotion campaigns. Such insights might be mostly similar in other Asian countries and/or in other developing countries, explicitly finding, it is an avenue for future research though.

\section{References}

Alden, D. L., Steenkamp, J. E. M., \& Batra, R. (2006). Consumer attitudes toward marketplace globalization: Structure, antecedents, and consequences. International Journal of Research in Marketing, 23(3), $227-239$.

Bakewell, C., Mitchell, V.W., \& Rothwell, M. (2006).UK Generation Y male fashion consciousness. Journal of Fashion Marketing and Management, 10(2), 169-180.

Cannon, H.M.,\& Yaprak, A. (2002).Will the real-world citizen please stand up! The many faces of cosmopolitan consumer behavior. Journal of International Marketing, 10(4), 30-52. 
Cleveland, M., \& Loroche, M. (2007).Acculturation to the global consumer culture: Scale development and research paradigm. Journal of Business Research, 60, 249-259.

Cleveland, M., Erdogan, S., Arikan, G., \&Poyraz, T. (2011).Cosmopolitanism, individual-level values and cultural-level values: A cross-cultural study. Journal of Business Research,64(9), 934-943.

Cleveland, M., Laroche, M., \&Hallab, R. (2013).Globalization, culture, religion, and values: Comparing consumption patterns of Lebanese Muslims and Christians. Journal of Business Research, 66(8), 958967.

Dunn, W. R., Wellman G. C., \& Bevan, J. A. (1994). Enhanced resistance artery sensitivity to agonists under isobasic compared with isometric conditions. American Journal of Physiology, 26(6), 417-455.

Demangeot, C., \& Sankaran, K.(2012).Cultural pluralism: Uncovering consumption patterns in a multicultural environment. Journal of Marketing Management, 28 (7-8), 760-783.

Dickson M. A., Lennon S. J., Montalto C. P.,Shen, D., \& Zhang, L. (2004). Chinese consumer market segments for foreign apparel products, Journal of Consumer Marketing, 21(5), 301-331.

Featherstone, M. (1995).Undoing culture: Globalization, postmodernism and identity. Sage Publications: London.

Garver, M. S., \& Mentzer, J.T. (1999). Logistics research methods: Employing structural equation modeling to test for construct validity. Journal of Business Logistics, 20(1), 33-57.

Gerbing, D. W., \& Anderson, J. C. (1988).An updated paradigm for scale development incorporating unidimensionality and its assessment. Journal of Marketing Research, XXV(May),186-192.

Gould, S. J., \& Stern, B. B.(1989).Gender schema and fashion consciousness. Psychology and Marketing, 6(2), 129-149.

Greco, A.J., \& Paksoy, C.H. (1989). Profiling the mature fashion-conscious apparel shopper. Akron Business and Economic Review, 20, 7-23.

Jin, B., \& Kang, J. H. (2011).Purchase intention of Chinese consumers toward a US apparel brand: A test of a composite behavior intention model. Journal of Consumer Marketing, 28(3), 187 - 199.

Jonathan, G., \& Mills, M.K. (1982).Fashion life cycle, self-concept, shopping orientation, and store patronage: An integrative analysis. Journal of Retailing, 58, 64-87.

LaTour, M.S., \& Henthorne, T.L. (1990).The PRC: An empirical analysis of country of origin product perceptions. Journal of International Consumer Marketing, 2(4), 7-36. 
Lee, R., \& Mazodier, M. (2015). The roles of ethnocentrism, animosity, and cosmopolitanism in sponsorship effects: A latent growth modeling approach. European Journal of Marketing, 49(5/6), 919-942.

Lertwannawit, A., \&Mandhachitara, R. (2012).Interpersonal effects on fashion consciousness and status consumption moderated by materialism in metropolitan men. Journal of Business Research, 65(10), 1408-1416.

Khare, A., Mishra, A., Parveen, C., \& Srivastava, R. (2011). Influence of consumers' susceptibility to interpersonal influence, collective selfesteem and age on fashion clothing involvement: A study on Indian consumers. Journal of Targeting, Measurement and Analysis for Marketing, 19(3/4), 227-242.

Khare, A. (2014). How cosmopolitan are Indian consumers?: A study on fashion clothing involvement. Journal of Fashion Marketing and Management, 18(4), 431 - 451.

Kotler, P., \& Keller, K. L. (2009). Marketing management. 13th Edition, New Delhi: Prentice Hall of India.

Kwak, H., Jaju, A., \& Larsen, T. (2006).Consumer ethnocentrism offline and online: The mediating role of marketing efforts and personality traits in the United States, South Korea, and India. Journal of the Academy of Marketing Science,34(3), 367-385.

Malhothra, N. (2005). Marketing research: An applied orientation. 4th Edition, New Delhi: Prentice Hall of India.

Manrai, L.A., Lascu, D.N., Manrai, A.K., \& Babb, H.W. (2001), A crosscultural comparison of style in Eastern European emerging markets. International Marketing Review, 18(3), 270-285.

Miller, N. B., Cowan, P. A., Cowan, C. P., Hetherington, E. M., \&Clingempeel, W. G. (1993). Externalizing in preschoolers and early adolescents: A cross-site replication of a family model. Developmental Psychology, 29,3-18.

Nam, J., Hamlin, R., Gam, H.J., Kang, J.H., Kim, J., Kumphai, P., Starr, C.,\& Richards, L. (2006).The fashion-conscious behaviours of mature female consumers. International Journal of Consumer Studies, 31(1), 102-108.

O'Connor, E. A., Friel, S., \& Kelleher, C. C. (1997).Fashion consciousness as a social influence on lifestyle behaviour in young Irish adults. Health Promotion International, 12(2), 135-139.

Patterson, M., \& Elliot, R. (2002).Negotiating masculinities: Advertising and the inversion of the male gaze. Consumption Markets and Culture, 5(3), 231-246. 
Rathnayaka, C. P. (2011).An empirical investigation of fashion consciousness of young fashion Consumers in Sri Lanka. Young Consumers, 12(2), 121-132.

Riefler, P., Diamantopoulos, A., \& Siguaw, J. A. (2012). Cosmopolitan consumers as a target group for segmentation. Journal of International Business Studies, 43, 285-305.

Riefler, P., \& Diamantopoulos, A. (2009). Consumer cosmopolitanism: Review and replication of the CYMYC scale. Journal of Business Research, 62, 407-419.

Skrbis, Z., Kendall, G., \& Woodward, I. (2004).Locating cosmopolitanism: Between humanist ideal and grounded social category theory. Culture and Society, 21(6), 115-136.

Summers, J.O. (1970).The identity of women's clothing fashion opinion leaders. Journal of Marketing Research, 7,178-185.

Walsh, G., Mitchell, V.W., \& Thuran, T.H. (2001).German consumer decision-making styles. The Journal of Consumer Affairs, (35),73-96.

Yoon, S. J., Cannon, M. H., \& Yaprak, A. (1996).Evaluating the CYMIC cosmopolitanism scale on Korean consumers. Advance in International Marketing, 7, 211-232.

Zhou, N.,\& Belk, R.W. (2004).Chinese consumer readings of global and local advertising appeals. Journal of Advertising, 33(3), 63-76. 